\title{
PERANCANGAN DASHBOARD PERENCANAAN PEMBANGUNAN IRIGASI DAERAH MENDUKUNG KETAHANAN PANGAN
}

\author{
Eko Aristanto, Syarif Hidayatullah ${ }^{1}$, Chandra Dinata ${ }^{2}$, Kuncoro Adi Prabowo ${ }^{3}$ \\ ${ }^{1}$ Fakultas Ekonomi dan Bisnis, Universitas Merdeka Malang \\ ${ }^{2}$ Fakultas ISIP, Universitas Merdeka Malang \\ ${ }^{3}$ Tenaga Ahli Sistem Informasi Dir. SUPD II Ditjen Bangda Kemendagri \\ e-mail: syarif.hidayatullah@unmer.ac.id
}

\begin{abstract}
Abstrak
Keberhasilan kebijakan ketahanan pangan perlu didukung ketersediaan air yang ditata dalam sistem irigasi yang baik. Perencanaan pembangunan irigasi di daerah dengan 66.391 daerah irigasi dengan dengan luasan 9.146.027 ha perlu penataan dalam data yang tersistematis. Dashboard perencanaan pembangunan irigasi daerah menjadi media integrasi berbagai perencanaan pembangunan sumber daya air yang dilauan oleh kabupaten/kota. Perancangan mengunakan model pengembangan sistem dengan pendekatan terstruktur yaitu linier sequential model atau waterfall model. Metode pelaksanaan kegiatan yang dilaksanakan untuk mencapai keberhasilan tujuan kegiatan ini melalui pemetaan indikator dan elemen data, survei lapangan, perancangan dashboard, focus group discussion. Lokasi pelaksanaan diskusi dan ujicoba database perencanaan pembangunan irigasi di laksanakan di 8 (delapan) kabupaten meliputi Kerawang, Subang, Indramayu, Cirebon, Purworejo, Banjarnegara, Purbalingga dan Jember. Keluaran yang dihasilkan kegiatan ini adalah dashboard perencanaan pembangunan irigasi daerah. Hasil evaluasi dan ujicoba menunjukan pengelolaan Dashboard Perencanaan Pembangunan Irigasi di Daerah telah berfungsi dengan baik.
\end{abstract}

Kata Kunci: Dashboard, Irigasi, Ketahanan Pangan

\section{A. Pendahuluan}

Ketahanan Pangan merupakan kebijakan strategis yang dilaksanakan pemerintah untuk mendorong produksi dalam rangka memenuhi penyediaan pangan bagi masyarakat. Ketahahan pangan merupakan sistem yang didalamnya terdiri sub.sistem yang meliputi ketersediaan, keterjangkauan dan pemanfaatan pangan(Ahmad Suryana, 2014). Berbagai faktor yang diharapkan dapat mendorong pencapaian ketahanan pangan meliputi : i) kondisi ekonomi, politik, sosial dan keamanan; ii) sarana dan prasarana; iii) teknologi yang dikembangkan; iv) pengadaan lahan yang tepat; dan v) iklim dan cuaca. Dengan merujuk pada berbagai faktor tersebut menunjukan pengadaan lahan yang tepat dan teknologi 
pertanian menjadi pilar penting. Kebutuhan lahan pertanian yang tepat akan meningkatkan produktivitas pertanian pada lahan tersebut (Cynthia Rahma Dewi et al., 2017).

Dalam kontek ketahanan pangan, maka optimalisasi pemanfaatan lahan pertanian perlu didukung dengan ketersediaan sumber air. Ketersediaan sumber air sangat penting bagi kegiatan pertanian, hal ini membutuhkan sistem irigasi yang baik dan dapat mengairi lahan pertanian tersebut. Ketersediaan sumber air dan kecukupannya akan mendorong kegiatan pertanian menjadi optimal yang mampu menjadi pengerak pertumbuhan ekonomi wilayah(Eko Aristanto, 2007). Untuk menjaga ketersediaan dan kecukupan air tersebut, langkah yang sedang dilakukan pemerintah adalah pelaksanaan modernisasi irigasi. Namun berkaitan dengan irigasi merujuk Undang-Undang No. 23 Tahun 2014 tentang pemerintah daerah menjelaskan bahwa irigasi diatur sesuai pembagian kewenangan yang terdiri pemerintah pusat, pemerintah provinsi dan pemerintah kabupaten (Kementerian Sekretaris Negara, 2014). Hal inilah yang menjadi perlunya melakukan inventarisasi data daerah irigasi secara komprehensip dan terintegrasi, menginggat keberadaan daerah irigasi yang menyebar di berbagai daerah.

Dalam Peraturan Menteri Pekerjaan Umum dan Perumahan Rakyat Republik Indonesia Nomor 14/PRT/M/2015 tentang Kriteria dan Penetapan Status Daerah Irigasi menjelasan daerah irigasi terbagi menjadi 3 (tiga) kewebangan yakni i) kewenangan pemerintah pusat, ii) kewenangan pemerintah provinsi dan iii) kewenangan pemerintah kabupaten/kota (Kementerian Pekerjaan Umum dan Perumahan Rakyat, 2015). Data Kementerian Pekerjaan Umum dan Perumahan menunjukan bahwa secara nasional terdapat 66.391 Daerah Irigasi dengan dengan luasan 9.146.027 Ha dengan pembagian berdasarkan kewenangan menjadi i) Daerah Irigasi kewenangan Pemerintah sebanyak 406 DI dengan luasan 3.142.532 Ha; ii) daerah irigasi kewenangan provinsi sebanyak 1.296 DI dengan luasan 1.634.467 Ha; dan iii) daerah Irigasi kewenangan kabupaten 64.689 DI dengan luasan 4.369.028 Ha. Adapun keberadaan 66.391 DI dengan luasan 9.146.027 Ha menyebar pada 34 Provinsi dan Kabupaten 416 Kabupaten (Eko Aristanto, 2019).

Direktorat Jenderal Bina Pembangunan Daerah mendapat mandat melakukan tugas untuk menyusun dan melaksanakan kebijakan terkait dengan penyelenggaraan urusan pemerintahan dan pembangunan daerah sesuai Peraturan Presiden Nomor 11 Tahun 2015 tentang Kementerian Dalam Negeri (Kementerian Dalam Negeri, 2019). Direktorat Jenderal Bina Pembangunan Daerah sebagai pembina pemerintah daerah memiliki peran penting 
dalam pemenuhan pelayanan dasar yang salah satunya pengelolaan sumber daya air termasuk di dalamnya pengelolaan irigasi. Urusan pengelolaan sumber daya air termasuk didalamnya pengelolaan irigasi merupakan kebijakan strategis nasional dalam rangka ketahanan pangan nasional (Kurniasih Budi, 2018).

Analisis situasi yang menunjukan bahwa dengan keberadaan 66.391 Daerah Irigasi dengan dengan luasan 9.146.027 Ha menyebar pada 34 Provinsi dan Kabupaten 416 Kabupaten dan aspek perencanaan pembangunan dilakukan Direktorat Jenderal Bina Pembangunan Daerah, maka terdapat beberapa kendala yang dihadapi yaitu : i) minimnya ketersediaan data dan pelaporan pemerintah daerah yang berkaitan dengan perencanaan pembangunan irigasi di daerah; ii) kesulitan melakuan monitoring dan evaluasi terhadap perencanaan pembangunan irigasi di daerah; iii) seringnya mutasi pegawai di daerah yang berdampak kelambanan pembaharuan data. Dengan berbagai kendala yang dihadapi tersebut, menyulitkan Direktorat Jenderal Bina Pembangunan Daerah melakukan pemetaan, monitoring dan evaluasi terhadap perencanaan pembangunan irigasi daerah.

Kondisi tersebut di atas, menjadi pemikiran awal perlunya pemanfaatan sistem informasi dalam mendukung manajemen internal pemerintahan saat ini merupakan sebuah keharusan. Dengan sistem informasi dapat meningkatkan produktivitas, mempercepat pengambilan keputusan, respons atas perubahan, meningkatkan pelayanan, efisiensi biaya (Rini Handayani, 2010), serta meningkatkan informasi kinerja pelayanan khususnya pada direktorat sinkronisasi urusan pemerintahan daerah II. Melalui Dashboard Perencanaan Pembangunan Irigasi Daerah yang baik dan berkualitas dapat mendorong pengolahan dan penyajian data yang relevan (memberikan manfaat bagi pemakainya)(Andi Nur Rachman et al., 2016), akurat (tidak bias dan harus jelas mencerminkan maksudnya), tepat waktu (timeliness), dan dapat dipercaya (reliability) (Kasim, 2018). Direktorat Jenderal Bina Pembangunan Daerah, dapat mempermudah dalam melakukan olah dan analisis serta menyajikan data, mencari basis data dan informasi yang tepat dan akurat untuk merumuskan kebijakan bidang irigasi di tingkat pusat dan daerah, mempermudah dalam merumuskan dan melakukan pembinaan yang lebih tepat. 


\section{B. Masalah}

Berdasarkan hal tersebut, maka yang menjadi masalah dalam pengabdian ini adalah:

1. Minimnya ketersediaan data dan pelaporan pemerintah daerah yang berkaitan dengan perencanaan pembangunan irigasi di daerah;

2. Kesulitan melakuan monitoring dan evaluasi terhadap perencanaan pembangunan irigasi di daerah;

\section{Metode Pelaksanaan.}

Perancangan Dashboard Perencanaan Pembangunan Irigasi Daerah mengunakan model pengembangan sistem dengan pendekatan terstruktur yaitu linier sequential model atau waterfall model. Metode pelaksanaan kegiatan yang dilaksanakan untuk mencapai keberhasilan tujuan kegiatan ini melalui pemetaan indikator dan elemen data, survei lapangan, perancangan dashboard, focus group discussion. Lokasi pelaksanaan diskusi dengan pemerintah kabupaten dan ujicoba Dashboard Perencanaan Pembangunan Irigasi di Daerah di laksanakan di 8 (delapan) kabupaten meliputi Kerawang, Subang, Indramayu, Cirebon, Purworejo, Banjarnegara, Purbalingga dan Jember. Pemulihan 8 (delapan) kabupaten tersebut merupakan penyedia lumbung pangan nasional. Pelaksanaan kegiatan dilakukan selama 4 (empat) bulan secara efektif mulai September-Desember 2019. Adapun alur tahapan perancangan dashboard perencanaan pembangunan irigasi di daerah mendukung ketahanan pangan, sebagai berikut:

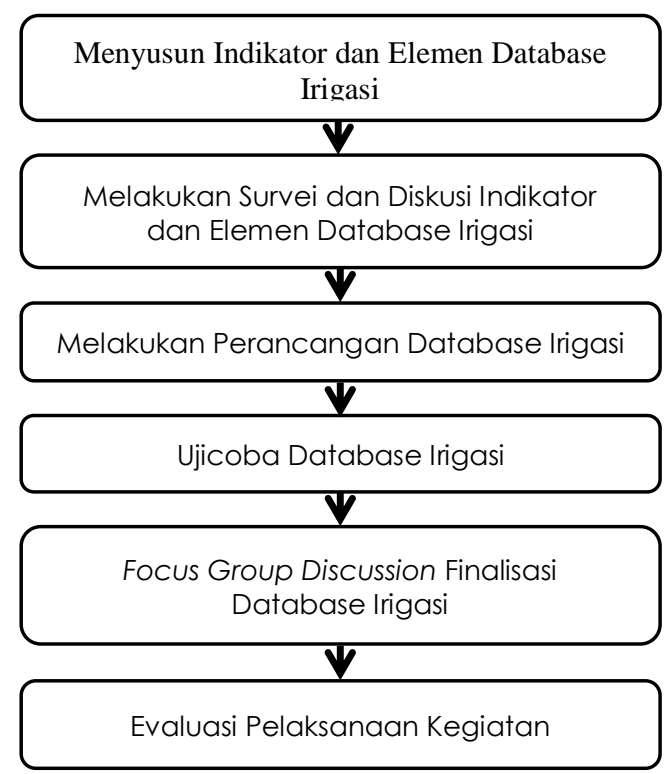

Gambar 1. Alur Tahapan Perancangan Dashboard Perencanaan Pembangunan Irigasi 


\section{Pembahasan}

Kegiatan pengabdian ini bertujuan untuk membantu masyarakat, pemerintah dan pengambil kebijakan untuk menyelesaikan suatu permasalahan yang dihadapi seperti yang dilakukan (Syarif Hidayatullah dkk., 2019) pengabdian yang dilakukan untuk membantu pengadaan alat dan pemberian fasilitas bagi KWT di Gn Kawi Kabupaten Malang, selanjutnya (Hidayatullah, Windhyastiti, Aristanto, Khouroh, \& Kusdyah, 2019)mengadakan pengabdian untuk memecahkan masalah dengan pembuatan mesin sangrai kopi serta memberikan pelatihan, senada dengan pengabdian yang dilakukan (Aristanto, Hidayatullah, Rachmawati, Waris, \& Khalikussabir, 2020) melakukan pengabdian dengan menyelesaikan masalah mitra Rumah Tahfiz Usia Dini (TAUD) berupa bantuan pelatihan dan perbaikan fasilitas belajar indoor dan outdoor. Perancangan Dashboard Perencanaan Pembangunan Irigasi di Daerah dimaksudkan adalah agar pengelolaan data dan informasi perencanaan, pelaksanaan, dan capaian menjadi tersistematisasi dan mudah dimanfaatkan untuk kepentingan pengembangan kebijakan dan pembinaan terhadap daerah. Adapun tujuan kegiatan ini adalah untuk membangun sebuah sistem informasi pengelolaan urusan pemerintahan daerah II sebagai bagian dari pelaksanaan tugas dan fungsi serta sarana fasilitasi Direktorat Jenderal Bina Pembangunan Daerah Kementerian Dalam Negeri atas pelaksanaan urusan Pemerintahan Daerah II di daerah. Adapun pelaksanaan kegiatan sesuai tahapa yang telah direncanakan meliputi:

\section{Tahap 1: Menyusun Indikator dan Elemen Data Dashboard Perencanaan Pembangunan Irigasi}

Penyusunan indikator dan elemen data dalam Perancangan Dashboard Perencanaan Pembangunan Irigasi di Daerah merujuk pada Peraturan Menteri Dalam Negeri Republik Indonesia No. 90 Tahun 2019 tentang Klasifikasi, Kodefikasi dan Nomenklatur Perencanaan Pembangunan dan Keuangan Daerah diidentifikasi menjadi 2 Menu Utama yakni: 1) Pengelolaan SDA dan Bangunan Pengaman Pantai pada Wilayah Sungai Lintas Daerah kabupaten/kota dengan 118 Indikator dan 378 Data dan 2). Pengembangan dan Pengelolaan Sistem Irigasi Primer dan Sekunder pada Daerah Irigasi yang luasnya 1000 Ha-3000 Ha dan Daerah Irigasi Lintas Daerah kabupaten Kota dengan 51 Indikator dan 177 Data. 
Vol.4 No. 1 April 2020

Tabel 1. Lokasi Kegiatan Kunjungan Lapangan/Uji Petik Kegiatan Pengembangan Database SDA/Irigasi.

\begin{tabular}{|l|c|c|}
\hline \multicolumn{1}{|c|}{ Menu dan Sub. Menu } & Indikator & Elemen Data \\
\hline $\begin{array}{l}\text { Pengelolaan SDA dan Bangunan Pengaman Pantai } \\
\text { pada Wilayah Sungai Lintas Daerah kabupaten /kota }\end{array}$ & & \\
\hline - Perencanaan Teknis & 20 & 51 \\
\hline - Pembangunan & 30 & 97 \\
\hline - Rehabilitasi dan Peningkatan & 37 & 176 \\
\hline - Operasi dan Pemeliharaan & 24 & 24 \\
\hline - Kelembagaan & 2 & 10 \\
\hline - Koordinasi dan Pembinaan & 5 & 19 \\
\hline & 118 & 377 \\
\hline $\begin{array}{l}\text { Pengembangan dan Pengelolaan Sistem Irigasi Primer } \\
\text { dan Sekunder pada Daerah Irigasi yang luasnya 1000 }\end{array}$ & & \\
$\begin{array}{l}\text { Ha-3000 Ha dan Daerah Irigasi Lintas Daerah } \\
\text { kabupaten/kota }\end{array}$ & & \\
\hline - Perencanaan Teknis & & 27 \\
\hline - Pembangunan & 5 & 41 \\
\hline - Rehabilitasi dan Peningkatan & 10 & 8 \\
\hline - Operasi dan Pemeliharaan & 20 & 22 \\
\hline - Kelembagaan & 11 & 6 \\
\hline - Koordinasi dan Pembinaan & 1 & 157 \\
\hline
\end{tabular}

Sumber: Analisis Data (2019)

Berdasaran pemetaan indikator dan elemen data yang digunakan dalam dashbord perencanaan pembangunan irigasi daerah dapat disimpulkan menu dan sub.menu dashboard perencanaan pembangunan irigasi menjadi 2 menu yakni: Utama yakni: 1) Pengelolaan SDA dan Bangunan Pengaman Pantai pada Wilayah Sungai Lintas Daerah Kabupaten /Kota dan Pengembangan dan 2) Pengelolaan Sistem Irigasi Primer dan Sekunder pada Daerah Irigasi yang luasnya 1000 Ha-3000 Ha dan Daerah Irigasi Lintas Daerah kabupaten/kota menjadi 6 sub. menu yang meliputi: 1). Perencanaan Teknis, 2). Pembangunan, 3). Rehabilitasi dan Peningkatan, 4). Operasi dan Pemeliharaan, 5). Kelembagaan dan 6). Koordinasi dan Pembinaan.

\section{Tahap 2: Survei dan Diskusi Indikator dan Elemen Dashboard Perencanaan Pembangunan Irigasi Daerah}

Pelaksanaan kegiatan kunjungan lapangan/uji petik pada kegiatan perancangan dashboard perencanaan pembangunan irigasi daerah dilakukan pada 3 (tiga) Provinsi dengan 
fokus pada Daerah Irigasi yang menjadi fokus optimalisasi dan modernisasi irigasinya, meliputi:

Tabel 2. Lokasi Kegiatan Kunjungan Lapangan/Uji Petik Kegiatan Pengembangan Database SDA/Irigasi

\begin{tabular}{lll}
\hline No. & Provinsi & Lokasi Kunjungan \\
\hline 1 & Jawa Barat & Kab. Cirebon \\
& & Kab. Indramayu \\
& & Kab. Karawang, \\
& & Kab. Subang \\
\hline 2 & Jawa Tengah & Kab. Purworejo \\
& & Kab. Banjarnegara \\
& & Kab. Purbalingga \\
\hline 3 & Jawa Timur & Kab. Jember \\
\hline
\end{tabular}

Kegiatan survei dilaksanakan pada 3 (tiga) provinsi meliputi: 1) Dinas Pekerjaan Umum dan SDA Provinsi Jawa Barat, 2) Dinas Pekerjaan Umum dan SDA Provinsi Jawa Tengah, dan 3) Dinas Pekerjaan Umum dan SDA Provinsi Jawa Timur. Sedangkan survei yang dilaksanaan pada 8 (delapan) labupaten meliputi: 1) Dinas Pekerjaan Umum dan Penataan Ruang Kabupaten Karawang, 2) Dinas Pekerjaan Umum dan Penataan Ruang Kabupaten Subang, 3) Dinas Pekerjaan Umum dan Penataan Ruang Kabupaten Indramayu, 4) Dinas Pekerjaan Umum dan Penataan Ruang Kabupaten Cirebon, 5) Dinas Pekerjaan Umum dan Penataan Ruang Kabupaten Purbalingga, 6) Dinas Pekerjaan Umum dan Penataan Ruang Kabupaten Banjarnegara, 7) Dinas Pekerjaan Umum dan Penataan Ruang Kabupaten Purworejo, dan 8) Dinas Pekerjaan Umum dan Penataan Ruang Kabupaten Jember.

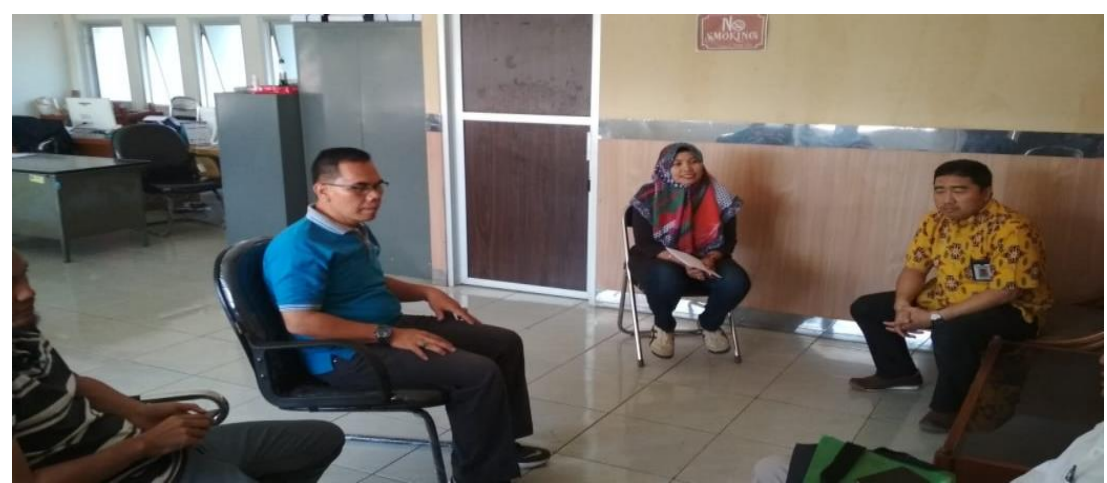

Gambar 2. Proses Kegiatan Diskusi Dengan Dinas PUPR Kabupaten Kerawang 


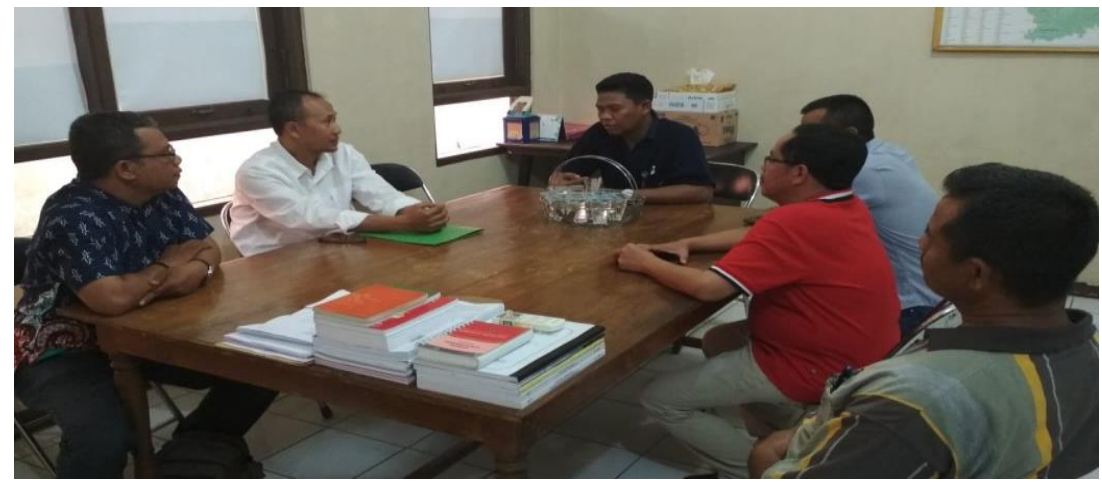

Gambar 3. Proses Kegiatan Diskusi Dengan Dinas PUPR Kabupaten Purbalingga

Pelaksanaan kegiatan kunjungan lapangan/uji petik pada kegiatan perancangan dashboard perencanaan pembangunan irigasi daerah terdapat beberapa masukan dari pemerintah daerah, meliputi:

1. Proses pengelolaan data mulai dari input sampai dengan pelaporan, diharapkan dengan menu navigasi yang memudahkan admin dan bersifat user friendly.

2. Menu utama dashboard tentunya harus memperhatikan tingkat ketersediaan data irigasi yang ada di daerah.

3. Pembaharuan data memiliki waktu yang bersifat semesteran, menginggat ketersediaan sumberdaya manusia di daerah yang sangat terbatas. Sementara beban perkejaan yang berkaitan dengan urusan daerah yang menjadi tanggung jawab wajib.

4. Dashboard dapat menjadi media melakukan monitoring dan evaluasi perencanaan pembangunan irigasi.

5. Pelaporan pada dashboard perencanaan pembangunan irigasi daerah berbentuk tabel dan grafis yang memudahkan penjelasan informasi dan proses pengambilan keputusan.

\section{Tahap 3: Perancangan Dashboard Perencanaan Pembangunan Irigasi di Daerah}

Perancangan dashboard mengunakan model pengembangan sistem dengan pendekatan terstruktur yaitu linier sequential model atau waterfall model (Dwi Januarita \& Teduh Dirgahayu, 2015). Adapun Businees Process dashboard perencanaan pembangunan irigasi daerah terdiri dari 7 tahapan yaitu identifikasi kebutuhan, perencanaan, perancangan prototipe, review prototipe, implementasi, deployment dan maintenance. Dari tiap tahap tersebut dijelaskan mengenai masukkan, proses keluaran pihak yang terlibat, waktu pelaksanaan yang digunakan pada setiap tahapan. Rancangan layout mockup dashboard perencanaan pembangunan irigasi daerah terdiri dari: 
1. Area 1: adalah tempat mengisikan alamat web dashboard perencanaan pembangunan irigasi daerah.

2. Area 2: merupakan kategori informasi yang dianalisis dalam dashboard perencanaan pembangunan irigasi daerah yang terdiri dari 2 menu utama yakni: 1) Pengelolaan SDA dan Bangunan Pengaman Pantai pada Wilayah Sungai Lintas Daerah Kabupaten /Kota dan 2). Pengembangan dan Pengelolaan Sistem Irigasi Primer dan Sekunder pada Daerah Irigasi yang luasnya 1000 Ha-3000 Ha dan Daerah Irigasi Lintas Daerah kabupaten Kota .

3. Area 3: adalah icon informasi lokus data yang dianalisis yaitu provinsi dan kabupaten.

4. Area 4: adalah area menampilkan fungsi grafik (chart) dan fungsi visual dari data perencanaan pembangunan irigasi daerah yang dianalisis.

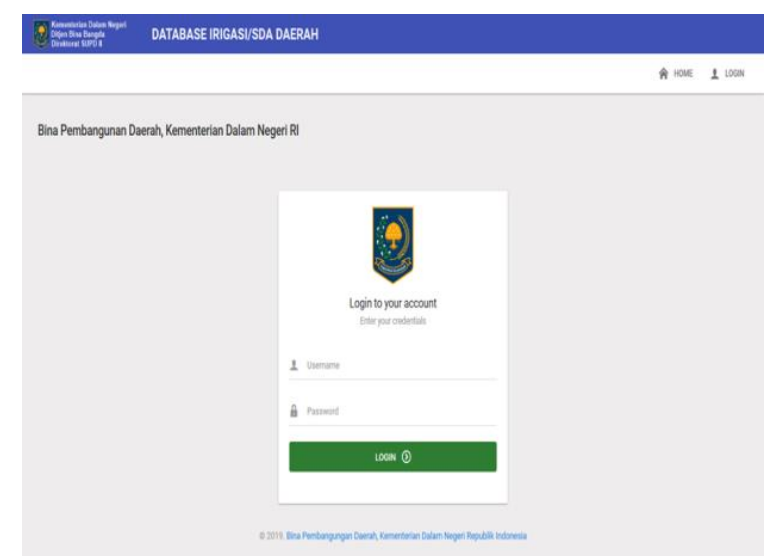

Gambar 4. Menu Utama Login Ke Dashboard Perencanaan Pembangunan Irigasi Daerah

Dalam perancangan dashboard perencanaan pembangunan irigasi daerah menyusun menu dan sub.menu adalah 1) Pengelolaan SDA dan Bangunan Pengaman Pantai pada Wilayah Sungai Lintas Daerah Kabupaten /Kota dan Pengembangan dan 2) Pengelolaan Sistem Irigasi Primer dan Sekunder pada Daerah Irigasi yang luasnya $1000 \mathrm{Ha}-3000 \mathrm{Ha}$ dan Daerah Irigasi Lintas Daerah kabupaten Kota menjadi 6 sub. menu yang meliputi : 1). Perencanaan Teknis, 2). Pembangunan, 3). Rehabilitasi dan Peningkatan, 4). Operasi dan Pemeliharaan, 5). Kelembagaan dan 6). Koordinasi dan Pembinaan. 


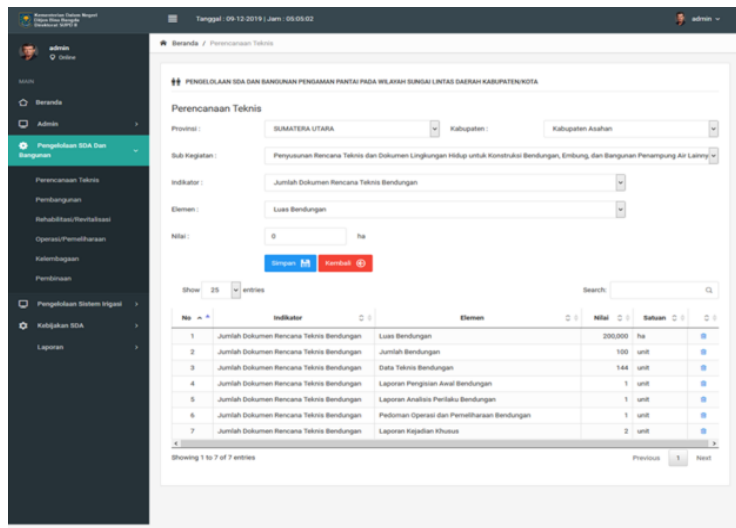

Gambar 5. Menu dan Sub. Menu Dashboard Perencanaan Pembangunan Irigasi Daerah

Dashboard perencanaan pembangunan irigasi daerah diperlukan untuk mengelola data dan informasi perencanaan, pelaksanaan dan capaian pembangunan irigasi daerah menjadi tersistematisasi dan mudah dimanfaatkan untuk kepentingan pengembangan kebijakan dan pembinaan terhadap daerah. Tampilan hasil analisis terhadap seluruh data perencanaan pembangunan irigasi daerah berbentuk fungsi grafik (chart) untuk membantu memudahan proses pengambilan keputusan dan lebih user friendly.

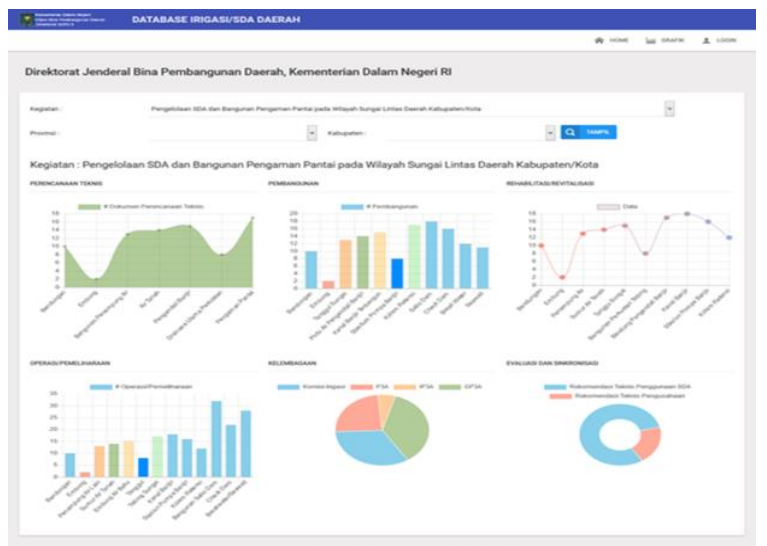

Gambar 6. Menu Hasil Analisis Data Perencanaan Pembangunan Irigasi Daerah

\section{Tahap 4: Ujicoba Dashboard Perencanaan Pembangunan Irigasi di Daerah}

Kegiatan ujicoba dashboard perencanaan pembangunan irigasi di daerah bertujuan menguji kehandalan kecepatan proses dan upadate dan tingkat pegetahuan dan pemahaman admin dalam melakukan proses pembaharuan data dan informasi yang beraitan dengan perencanaan pembangunan irigasi daerah. Kegiatan ini berbentuk simulasi kepada masing- 
masing admin dinas PUPR pada 8 kabupaten meliputi Kerawang, Subang, Indramayu, Cirebon, Purworejo, Banjarnegara, Purbalingga dan Jember.

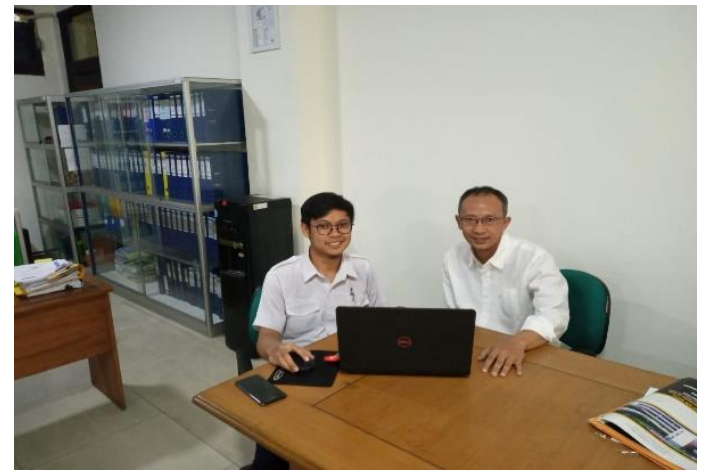

Gambar 7. Simulasi Dashboarh Perencanaan Pembangunan Irigasi Daerah di Kabupaten Jember

\section{Tahap 5: Focus Group Discussion Finalisasi Dashboard Perencanaan Pembangunan Irigasi}

Kegiatan focus group discussion finalisasi dashboard perencanaan pembangunan irigasi daerah ini, dalam rangka mendapatkan masukan dari pemerintah daerah dan kementerian teknis berkaitan dengan menu, sub.menu, tampilan dan pelaporan dashboard perencanaan pembangun- an irigasi di daerah.

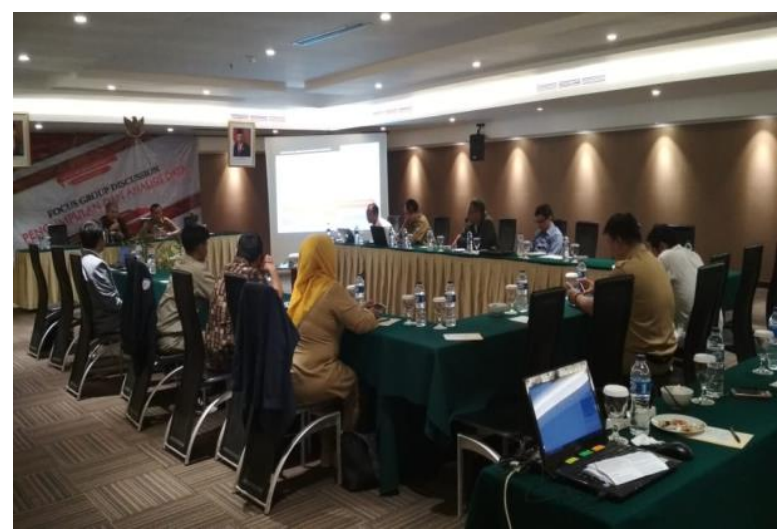

Gambar 8. Simulasi Dashboard Perencanaan Pembangunan Irigasi Daerah di Kabupaten Jember.

Adapun hasil kegiatan focus group discussion finalisasi dashboard perencanaan pembangunan irigasi daerah, meliputi:

1. Dashboard perencanaan pembangunan irigasi daeah wajib untuk melakukan pengamanan data irigasi daerah. 
2. Perlu kegiatan pelatihan pada seluruh admin yang mengoperasionalkan dashboard perencanaan pembangunan irigasi daerah dengan membagi wilayah barat, tengah dan timur agar semua pemerintah daerah dapat memahami fungsi utama dashboard perencanaan pembangunan irigasi daerah.

3. Penyiapan hardware yang diperlukan dalam mengelola dashboard perencanaan pembangunan irigasi daerah, serta menginstall semua software yang diperlukan.

4. Menyusun panduan bagi pengoperasionalan dashboard perencanaan pembangunan irigasi daerah

\section{Tahap 6: Evaluasi Pelaksanaan Kegiatan}

Tahapan terakhir dalam kegiatan ini melakukan evaluasi terhadap pelaksanaan kegiatan dengan melakukan uji respon terhadap dashboard perencanan pembangunan irigasi daerah dalam bentuk kuesioner umpan balik. Adapun indikator evaluasi yang digunakan meliputi : aspek pemahaman terhadap dashboard, aspek kemudahan proses input data, aspek kemudahan pemuktahiran data, aspek keberfungsian dashboard dan aspek kebermanfaatan dashboard. Adapun hasil menunjukan bahwa aspek pemahaman terhadap dashboard sebesar 93,75 \%, aspek kemudahan proses input data sebesar 87,\% \%, aspek kemudahan pemuktahiran data sebesar $81,25 \%$, aspek keberfungsian dashboard sebesar $100 \%$ dan aspek kebermanfaatan dashboard sebesar 100\%. Hasil tersebut menjelaskan bahwa admin yang akan mengunakan dashboard perencanan pembangunan irigasi daerah dapat bekerja baik dan mampu mengoptimalkan fungsi dashboard perencanan pembangunan irigasi daerah sehingga dapat memberikan kemanfaatan bagi pelaksanaan monitoring dan evaluasi kegiatan perencanaan pembangunan irigasi daerah.

\section{E. Kesimpulan}

Berdasarkan hasil pelaksanaan kegiatan ini dapat dioperasikan Dashboard Perencanaan Pembangunan Irigasi di Daerah yang berdasarkan Peraturan Menteri Dalam Negeri Republik Indonesia No. 90 Tahun 2019 tentang Klasifikasi, Kodefikasi dan Nomenklatur Perencanaan Pembangunan dan Keuangan Daerah. Dashboard Perencanaan Pembangunan Irigasi di Daerah dioperasionalkan oleh Admin Direktorat Sinkronisasi Urusan Pemerintah Daerah II Direktorat Jenderal Bina Pembangunan Daerah, Kementerian Dalam Negeri dan proses pembaharuan data dapat dilakukan oleh pemerintah daerah. Adapun beberapa rekomendasi bagi Dashboard Perencanaan Pembangunan Irigasi Daerah, meliputi: 
i) menyempurnakan sistem berdasarkan masukan dan evaluasi, melakukan updating data yang dilaksanakan oleh staf lingkungan Subdit Pekerjaan Umum Direktorat SUPD II; ii) melaksanakan pengelolaan Dashboard Perencanaan Pembangunan Irigasi di Daerah secara terintegrasi dan terkoordinasi. Serta membahas dan mengembangkan standar-standar serta tatalaksana pengelolaan data dan informasi Dashboard Perencanaan Pembangunan Irigasi Daerah. Standar dan tatalaksana tersebut kemudian dijadikan kesepakatan bersama sehingga mengikat. Bila perlu disiapkan peraturan dan regulasi yang diperlukan untuk memberikan kekuatan bagi implementasi kesepakatan bersama tersebut; dan iii) menginggat Dashboard Perencanaan Pembangunan Irigasi Daerah berbagai ketersediaan data dan informasi banyak yang bersumber dari pemerintah daerah, diharapkan Admin selalu berkoordinasi dengan pemerintah daerah untuk melakukan update Dashboard Perencanaan Pembangunan Irigasi di Daerah.

\section{DAFTAR PUSTAKA}

Ahmad Suryana. (2014). Menuju Ketahanan Pangan Indonesia Berkelanjutan 2025: Tantangan dan Penanganannya. Forum Penelitian Agra Ekonomi, Vol. 32 No. 2, 123-135.

Andi Nur Rachman, Cecep Muhamad Sidik Ramdani, \& Siti Hasanah Nisya. (2016). Implementasi Sistem Dashboard pada Aplikais Kependudukan (Studi Kasus: Dinas Kependudukan dan Pencatatan Sipil Kabupaten Ciamis). Seminar Nasional Teknologi Informasi Dan Komunikasi 2016, 175-180.

Aristanto, E., Hidayatullah, S., Rachmawati, I. K., Waris, A., \& Khalikussabir, K. (2020). Peningkatan Fasilitas Bagi Tahfizh Anak Usia Dini "Kuttab Rumah Quran” Menuju Persaingan Pendidikan Anak Pra Sekolah. JIPEMAS: Jurnal Inovasi Hasil Pengabdian Masyarakat. https://doi.org/10.33474/jipemas.v3i1.4763.

Cynthia Rahma Dewi, Eko Andi Suryo, \& As'ad Munawir. (2017). Peningkatan Kinerja Operasi dan Pemeliharaan Jaringan Irigasi Pacal Kabupaten Bojonegoro, Jawa Timur. Rekayasa Sipil, Vol. 11, No. 2, 124-134.

Dwi Januarita, \& Teduh Dirgahayu. (2015). Pengembangan Dashboard Information System (DIS): Studi Kasus Lembaga Penelitian dan Pengabdian Masyarakat (LPPM) ST3 Telkom Purwokerto. Jurnal Infotel, Vol. 7, No. 2, 165-169.

Eko Aristanto. (2007). Evaluasi Dampak Sosial Ekonomi Program Pengembangan Kawasan di Propinsi Jawa Timur. Universitas Merdeka Malang, LPPM.

Eko Aristanto. (2019). Efektivitas Skema Modalitas Result Based Lending (RBL) pada Implementasi Program Integrated Participatory Development \& management of 
Irrigation Program (IPDMIP) Di Provinsi Banten. LPPM Universitas Merdeka Malang.

Kasim. (2018). Analytic Dashboard Untuk Penilaian Capaian Kinerja Dengan Metode Smart Decision Support System. Inspiration: Jurnal Teknologi Informasi Dan Komunikasi, Volume 8, Nomor 2, 144-154.

Kementerian Dalam Negeri. (2019). Peraturan Menteri Dalam Negeri Republik Indonesia No. 90 Tahun 2019 tentang Klasifikasi, Kodefikasi dan Nomenklatur Perencanaan Pembangunan dan Keuangan Daerah. Kementerian Dalam Negeri.

Kementerian Pekerjaan Umum dan Perumahan Rakyat. (2015). Peraturan Menteri Pekerjaan Umum dan Perumahan Rakyat Republik Indonesia Nomor 14/PRT/M/2015 tentang Kriteria dan Penetapan Status Daerah Irigasi. Kementerian Pekerjaan Umum dan Perumahan Rakyat.

Kementerian Sekretaris Negara. (2014). Undang-Undang Nomor 23 Tahun 2014 tentang Pemerintah Daerah. Kementerian Sekretaris Negara.

Kurniasih Budi. (2018, Mei). Pengelolaan Irigasi dan Drainase Dukung Ketahanan Pangan. Kompas.Com.https://ekonomi.kompas.com/read/2018/05/12/122105126/pengelolaan -irigasi-dan-drainase-dukung-ketahanan-pangan?page=all.

Rini Handayani. (2010). Analisis Faktor-Faktor yang Menentukan Efektivitas Sistem Informasi pada Organisasi Sektor Publik. Jurnal Akuntansi Dan Keuangan, Vol. 12, No. 1, 26-40.

Hidayatullah, S., Windhyastiti, I., Aristanto, E., Khouroh, U., \& Kusdyah, I. (2019). PKM Kopi Rakyat Kelompok Wanita Tani ( KWT) “ Ngudi Rahayu “ Desa Kebobang Wonosari Kabupaten Malang. 4(1), 130-136.

Syarif Hidayatullah, Irany Windhyastiti, Eko Aristanto, Umu Khouroh, \& Ike Kusdyah Rachmawati. (2019). PKM Kopi Rakyat Kelompok Tani (KWT) "Ngudi Rahayu" Desa Kebobang Wonosari Kabupaten Malang. Jurnal Akses Pengabdian Indonesia, Vol 4, No 2, 130-136. https://doi.org/10.1016/j.agsy.2010.12.004 